\title{
INTERNAL WaVe-Driven SuRface CURRENTS FROM HF RADAR
}

\section{Observations from}

recent experiments

. . . have revealed

internal wave

signatures.

\author{
By Lynn K. Shay
}

S quency (HF) radar have revealed that not only are the low-frequency and tidal currents resolved by the measurement, higher-frequency motions are also contained within the signals. These higherfrequency current oscillations are within the internal wave continuum from the buoyancy to the inertial frequencies, including the excitation of semidiurnal internal tides forced by a barotropic tide propagating over the shelf-break (Baines, 1986; Paduan and Cook, 1997). Another complicating feature in the coastal regime is oceanic frontal structure that significantly influences internal wave variability because of the background vorticity fields (Mooers, 1975; Kunze, 1985). However, little is known about the internal wave interactions with coastal ocean fronts where these vorticities may be considerably larger than in the deep ocean because of the larger density contrast between the water masses. Synoptic observations of the horizontal flow structure from HF radar provides the spatial context for moored and shipbased measurements to assess the impact of coastal fronts on the internal wave climate.

Observations from recent experiments using the University of Miami's Ocean Surface Current Radar (OSCR) (Shay et al., 1995, 1997), and the U.S. Coast Guard (USCG)-sponsored Ocean Pollution Research Center (OPRC) experiments in the Florida Keys (L.K. Shay, T.N. Lee, E.J. Williams, H.C. Graber and C.G.H. Rooth, unpublished data) have revealed internal wave signatures. These data will be used to show the linkage between HF-derived surface currents and current profiles acquired from an acoustic Doppler current profiler (ADCP) with respect to the internal wave signals.

\section{Observations}

The HF radar system mapped the coastal ocean currents over a $30 \times 45 \mathrm{~km}$ domain at 20 -min intervals with a horizontal resolution of $1.2 \mathrm{~km}$ along the Florida Keys during OPRC-2. Over a 25-d period from 18 May to 13 June 1994, five

Lynn K. Shay, University of Miami. Miami. FL, 33149. USA. percent of the surface current images were missing yielding a high data return as found in previous experiments. An upward-looking, narrow-beam ADCP was moored in $150 \mathrm{~m}$ off Looe Key in the radar domain and provided current observations at 5-m intervals from 15- to $130-\mathrm{m}$ depths. Surface current data were averaged at one-half hourly intervals to coincide with the ADCP sampling interval and rotated into bottom topographic coordinates.

Data acquired over a 10 -d period during the OPRC-2 experiment indicated submesoscale vortices located along the inshore side of the Florida Current that were aligned with the 150 -m isobath. Between 22 May (Yearday 142) to 27 May (Yearday 147), the along-shelf flow reversed direction as the Florida current moved further offshore. The maximum cross-shelf component exceeded $25 \mathrm{~cm}$ $\mathrm{s}^{-1}$ toward the north whereas the along-shelf current exceeded $150 \mathrm{~cm} \mathrm{~s}^{-1}$ when the Florida Current was located over the mooring (Fig. 1). Root mean square (rms) differences were $18 \mathrm{~cm} \mathrm{~s}^{-1}$ between the surface and $15-\mathrm{m}$ records. Previous estimates of rms differences between surface and subsurface currents from HIRES-2 were $10-14 \mathrm{~cm} \mathrm{~s}^{-1}$ because of mesoscale variability associated with low-frequency baroclinic currents of the Gulf Stream and internal waves (Shay et al., 1995: Chapman et al., 1997). In a time-averaged sense, Graber et al. (1997) found that $\geq 50 \%$ of these differences may have been due to a combination of surface wave and wind-induced currents and these baroclinic currents. Recent comparisons between surface and subsurface $(4 \mathrm{~m})$ currents from vector measuring current meters (VMCM) acquired during the $\mathrm{Na}$ tional Science Foundation Coastal Ocean Processes (NSF CoOP) and ONR Duck94 experiments indicated $\mathrm{rms}$ differences of $7 \mathrm{~cm} \mathrm{~s}^{-1}$ (Shay et al., 1997). These observations were at the uncertainty limits of resolvable processes from the OSCR and VMCM instruments (Weller and Davis, 1980).

\section{Surface Current Images}

Observed current time series were decomposed into the subinertial ( $>48 \mathrm{~h}$ ), tidal, inertial ( $29 \mathrm{~h})$, high-frequency $(5 \mathrm{~h})$, and residual currents. Based 


$142,144,146,148,150,152$

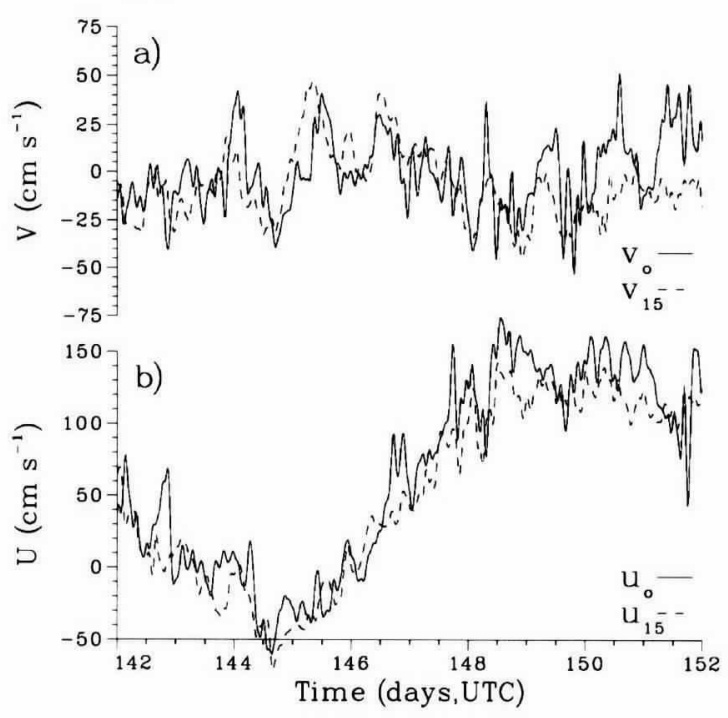

Fig. 1: (a) Cross-shelf and (b) along-shelf surface (-) and $15 \mathrm{~m}(---)$ current time series $\left(\mathrm{cm} \mathrm{s}^{-1}\right)$ from 22 May (YD 142) to 1 June (YD 152) 1994 during $O P R C-2$.

on the peaks in the rotary spectra (Shay et al., 1995, 1997), a harmonic analysis of the tides was performed to determine the diurnal and semidiurnal tidal constituents and removed to form detided records. Using a Lanczos-square window, the detided currents were low-pass filtered at $48 \mathrm{~h}$, bandpass filtered between 25 and $38 \mathrm{~h}$, and high-pass filtered at $8 \mathrm{~h}$ to form subinertial, near-inertial and high-frequency current time series, respectively.
The width of the near-inertial band reflects the subinertial vorticities described below. In addition, the 25-d time series adequately resolved the nearinertial and diurnal tide contributions.

Observed surface velocities indicated structure in the surface velocity field including submesoscale eddylike vortices (Fig. 2). Based on the observed surface current images, these submesoscale vortices translated from the western part of the domain toward the eastern part at a rate of $25-30 \mathrm{~km} \mathrm{~d}^{-1}$. This translation rate was not only above the expected envelope of low-frequency baroclinic features such as eddies and rings, but the direction of movement was opposite to coastally-trapped waves propagating along the eastern coast of basins. Although subinertial flows indicated little evidence of this submesoscale feature, the observed signal was embedded in the near-inertial flows. Based on a series of leastsquare fits, the horizontal wavelength of this feature was $\sim 35 \mathrm{~km}$ with velocities of up to $30 \mathrm{~cm} \mathrm{~s}^{-1}$ (Fig. 2b). Thus this submesoscale variability was embedded in the near-inertial current signals.

\section{Vertical Structure}

As shown in Figure 3, high-frequency surface and subsurface signals had 4-5-h periods and vertical wavelengths of 20-25 m (Shay, 1996). During the period of subinertial flow change from YD 144 to 146 , the velocities of these high-frequency motions were about $15 \mathrm{~cm} \mathrm{~s}^{-1}$ and were highly intermittent. The subinertial current velocities were shifted from $-40 \mathrm{~cm} \mathrm{~s}^{-1}$ in the surface layer to 150 $\mathrm{cm} \mathrm{s}^{-1}$ at 40-m depth as the Florida Current moved back over the mooring. A near-inertial current

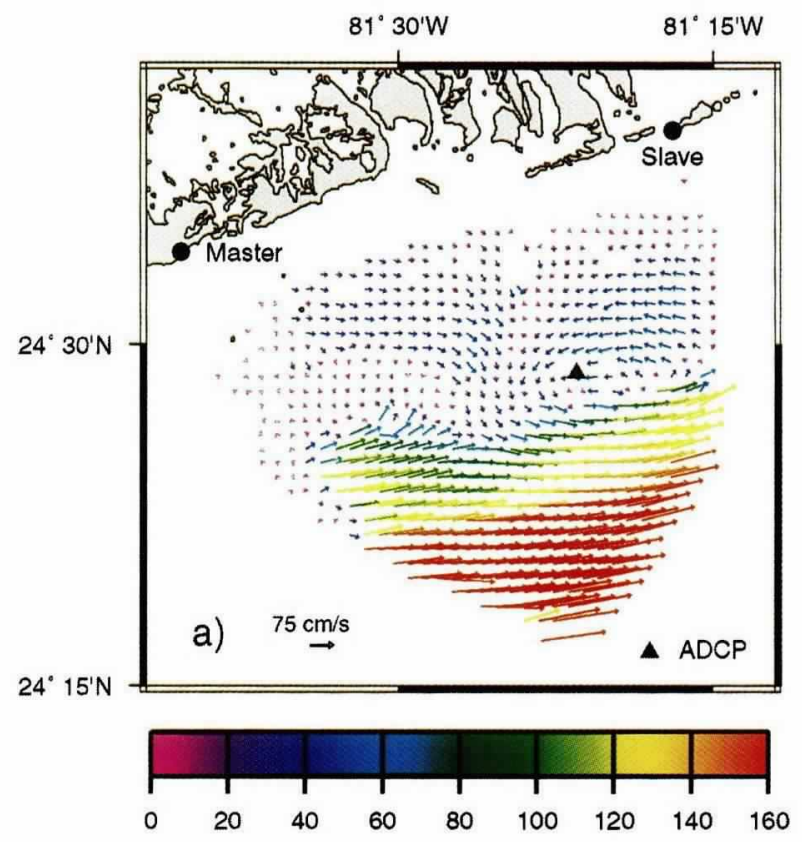

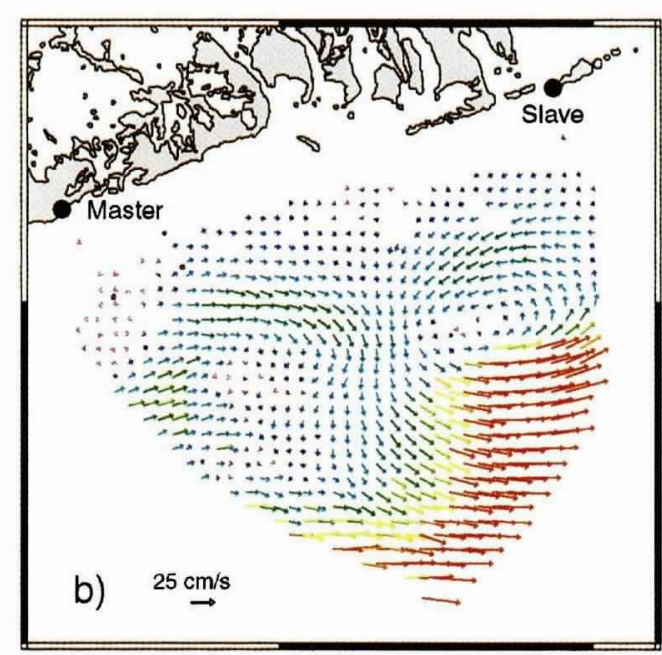

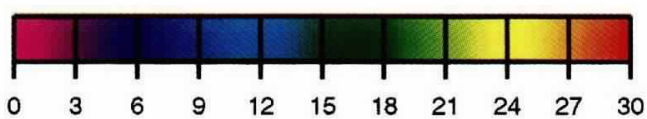

Observed surface

velocities indicated structure in the surface velocity field including submesoscale eddylike vortices.

Fig. 2: (a) Observed and (b) near-inertial surface flows from the OPRC-2 experiment in the Florida Keys at 1800 UTC 25 May 1994. The color of the arrows represents the strength of the current as per the color bars in $\mathrm{cm} \mathrm{s}^{-1}$. 


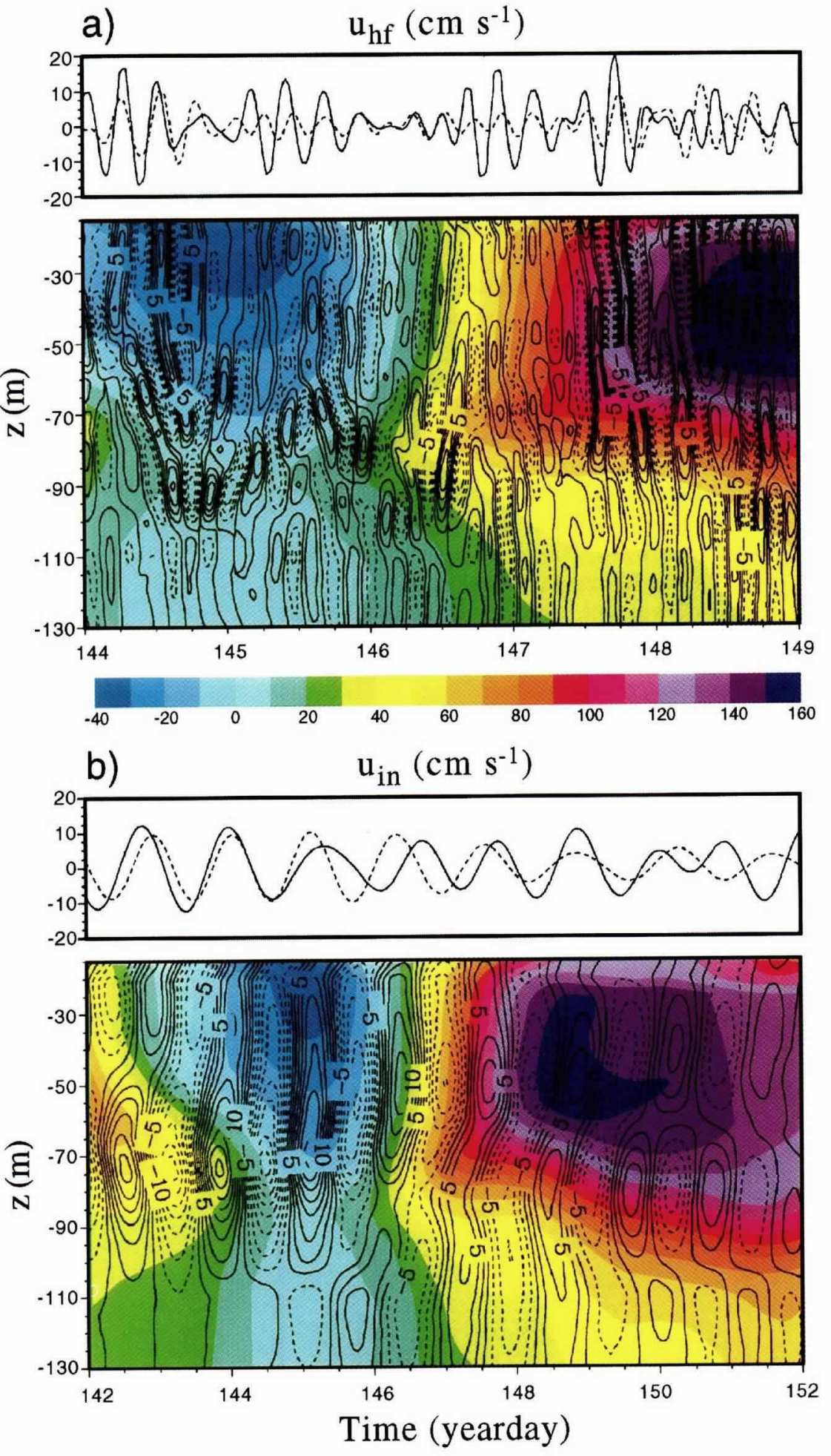

Fig. 3: Comparison (top panels) between surface (solid) and $15 \mathrm{~m}$ (dashed) currents and contoured along-shelf current profiles (bottom panels) for (a) high-frequency and $(\boldsymbol{b})$ near-inertial components $\left(\mathrm{cm} \mathrm{s}^{-1}\right)$ from an ADCP deployed in the OPRC-2 experiment from 22 May to I June 1994 superimposed on the subinertial flow (color). Panel (a) represents a 5-d timeseries compared with the 10-d series in $(\boldsymbol{b})$. Contour interval is $2.5 \mathrm{~cm} \mathrm{~s}^{-1}$ in the bottom panels.

episode also occurred from YD 142 to 152 when the wave burst had an amplitude of $\sim 20 \mathrm{~cm} \mathrm{~s}^{-1}$ and vertical wavelengths of $\sim 50 \mathrm{~m}$ (Fig. 3b). Along- shelf surface current signals were initially in phase with the subsurface currents through YD 147 when the signals indicated phase separation. The opposite situation occurred in the cross-shelf velocity components (not shown) with respect to the phases. The vertical structure of these oscillations indicated a first or second baroclinic mode vertical dependence compared with a second or third baroclinic mode structure for the high-frequency current signals.

\section{Subinertial Flow Vorticity}

Kunze (1985) showed that the vorticity associated with geostrophically balanced currents alters the passband of allowable near-inertial frequencies. An effective Coriolis parameter was defined

$$
\mathrm{f}_{\text {eff }}=\mathrm{f}+1 / 2\left\{\partial \mathrm{V}_{\mathrm{g}} / \partial \mathrm{x}-\partial \mathrm{U}_{\mathrm{g}} / \partial \mathrm{y}\right\},
$$

where $f$ represents the local Coriolis parameter and $\mathrm{U}_{\mathrm{g}}$ and $\mathrm{V}_{\mathrm{g}}$ are the geostrophic current components. Here the subinertial current records are used as a proxy for these geostrophic components. In an anticyclonically rotating vorticity regime, the frequency of the near-inertial motions will be $<\mathrm{f}_{\text {eff }}$ as near-inertial motions are trapped and advected by the subinertial flow where amplification of the near-inertial wave signal may occur. By contrast, the effective Coriolis parameter is shifted above $\mathrm{f}$ in cyclonically rotating vorticity regimes as nearinertial motions propagate away from the area.

As shown in Figure 4, the horizontal structure of the near-inertial flows on 25 May was affected by the subinertial flow vorticity, which ranged between $\pm 2 \mathrm{f}$. The center of the submesoscale feature, as depicted by the near-inertial flow, was located along the inshore edge of the Florida Current where normalized vorticity changed sign from cyclonic $(>0)$ to anticyclonic $(<0)$ rotation. There was a strong convergence zone of near-inertial motions centered in the domain. A large fraction of the near-inertial surface current motions were apparently trapped and advected by the anticyclonically rotating subinertial flow vorticity. In this regime, the near-inertial waves cannot propagate into the positive vorticity regime because of the larger $\mathrm{f}_{\text {eff }}$ as per equation (1). This is one explanation of why the near-inertial energy is amplified in the negative vorticity trough inshore of the Florida Current. In addition, the vertical structure of the near-inertial motions suggests a possible amplification of the signal in the areas of strong subinertial current shear consistent with previous theories (Mooers, 1975; Kunze, 1985). Previous observations have also found spin-off eddies because of frontal instabilities as the Florida current moves across the shelf break in this complex regime (Lee, 1975).

\section{Summary}

Emerging technological capabilities of in situ and remote sensing observational techniques are 

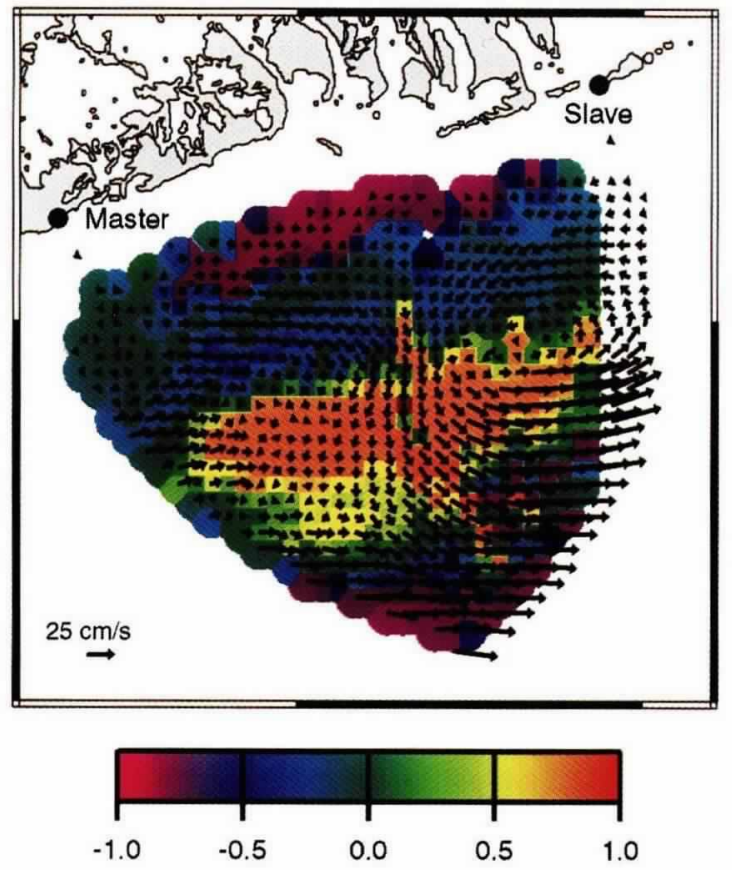

Fig. 4: Near-inertial currents $(\rightarrow)$ superposed on the subinertial flow vorticity (color) normalized by $2 f$ ( $f$ is the local Coriolis parameter) from the OPRC-2 experiment at 1800 UTC on 25 May.

providing reliable, spatially evolving snapshots of submesoscale to mesoscale oceanic flows (Shay, 1997). Surface current observations from several experiments in the United Kingdom (Prandle, 1987) as well as the HIRES, OPRC, and Duck94 experiments have suggested that the HF radar-derived surface currents agree well with subsurface current measurements and detect not only the lowfrequency and tidal currents, but also internal waves. The surface convergence and divergence patterns of internal wave motions are intrinsically linked to the pycnocline (Gasparovic et al., 1988) and the vertical structure oscillations in the currents. The combination of high-resolution ADCPs embedded within the HF radar grid provides an effective approach to observe evolving, 3-dimensional processes of the internal waves. Thus the 2dimensional representation of these surface motions and their interactions with the subinertial flows associated with coastal frontal structure observed from HF radar measurements provides a new view to improve our understanding of wave dispersion in the coastal regime.

\section{Acknowledgments}

The dedicated efforts of Duncan Ross and Jorge Martinez are sincerely appreciated. Hans
Graber, Chris Boyce, Nick Peters, John Hargrove, Brian Haus, and Louis Chemi were involved in the experimental setup and data acquisition efforts. Tom Lee and Liz Williams provided the ADCP data, Jean Carpenter drafted figures, and Terry Faber assisted in the programming effort. The author acknowledges funding support from the USCG-sponsored OPRC (RD9401) directed by Chris Mooers and the continuing support of the ONR Remote Sensing Program through grants N00014-91-J-4133 and N00014-96-1-1101. The Florida Space Grant Consortium under the auspices of the National Aeronautics and Space Administration provided funding for a summer undergraduate internship for Gretzali Perez from the University of Puerto Rico who assisted in processing the observations.

\section{References}

Baines, P.G., 1986: Internal tides, internal waves and near-inertial motions. In: Baroclinic Processes On Continental Shelves. C.N.K. Mooers, ed. American Geophysical Union, Washington DC, 19-31.

Chapman, R.D., L.K. Shay, H.C. Graber, J.B. Edson, A. Karachintsev, C.L. Trump and D.B. Ross, 1997: Intercomparison of HF radar and ship-based current measurements. J. Geophys. Res., 102, 18,737-18,748.

Gasparovic, R.F., J.R. Apel and E.S. Kasische, 1988: An overview of the SAR Internal Wave Experiment. $J$. Geophys. Res., 93, 12304-12316.

Graber, H.C., B.K. Haus, R.D. Chapman and L.K. Shay, 1997: HF radar comparisons with moored estimates of current speed and direction: expected differences and implications. J. Geophys. Res., 102, 18,749-18,766.

Kunze, E., 1985. Near-inertial wave propagation in geostrophic shear. J. Phys. Oceanogr., 15, 544-565.

Lee, T.N., 1975: Florida current spin-off eddies. Deep-Sea Res., 22, 753-765.

Mooers, C.N.K., 1975: Several effects of a baroclinic current on the cross-stream propagation of inertial-internal waves. Geophys. Fluid Dyn., 6, 245-275.

Paduan, J. and M.S. Cook, 1997: Mapping surface currents in Monterey Bay with CODAR-type HF radar. Oceanography, 10, 49-52.

Prandle, D. 1987: The fine-structure of nearshore tidal and residual circulations revealed by HF radar surface current measurements. J. Phys. Oceanogr., 17, 231-245.

Shay, L.K., 1996: Observed internal wave driven surface currents from HF radar. In: Coastal Oceanic Conference and Atmospheric Prediction. American Meteorological Society, Boston, 296-303.

, in press: Mesoscale Oceanic Flows. In: Handbook of Fluid Dynamics. Richard Johnson, ed. CRC Press, Boca Raton, FL.

, H.C. Graber, D.B. Ross and R.D. Chapman, 1995: Mesoscale ocean surface current structure detected by HF radar. J. Atmos. Ocean. Tech., 12, 881-900.

$\longrightarrow$ S.J. Lentz, H.C. Graber and B.K. Haus, 1997: Current structure variations detected by HF radar and vector measuring current meters. J. Atmos. Ocean. Tech., (in press).

Weller, R.A. and R.E. Davis, 1980: A vector measuring current meter. Deep-Sea Res., 27, 575-582.
... HF radar-de-

rived surface currents

agree well with sub-

surface current mea-

surements . . . 